\title{
Russia Beyond Indonesia: Image Transforming Effort Through Public Diplomacy
}

\author{
Russia Beyond Indonesia: Upaya Mengubah Citra \\ Melalui Diplomasi Publik
}

\author{
Chandra Purnama, Sasti Khoirunnisa, \\ Anggia Utami Dewi \& Dina Yulianti \\ Universitas Padjadjaran
}

\begin{abstract}
ABSTRAK
Survei menunjukkan bahwa sekitar 40\% citra Rusia di tengah publik Indonesia adalah citra negatif. Indonesia bahkan disebut sebagai negara dengan persepsi negatif tertinggi terhadap Rusia di kawasan Asia Tenggara. Artikel ini memaparkan upaya Rusia memperbaiki citranya di hadapan publik Indonesia melalui diplomasi publik dengan menggunakan media Russia Beyond (RBTH Indonesia). Penulis menggunakan konsep tiga dimensi diplomasi publik dari Leonard, Stead, dan Smewing (2002) sebagai alat analisis, yaitu news management, strategic communications, dan relationship building. Data yang digunakan dalam artikel ini didapatkan dari website dan media sosial Russia Beyond, wawancara dengan dua narasumber terkait, dan studi literatur. Penulis menyimpulkan bahwa diplomasi publik yang dilakukan oleh Rusia telah menggunakan tiga dimensi diplomasi publik dengan cukup baik namun perlu dilakukan penelitian lanjutan mengenai dampak upaya ini bagi perbaikan citra Rusia di Indonesia.
\end{abstract}

Kata-kata kunci: diplomasi publik Rusia, Indonesia, Rusia, Russia Beyond Indonesia

Survey shows that around 40\% of Russia's image in the public of Indonesia is relatively negative. Indonesia is referred to as a country with the highest negative perception of Russia in the Southeast Asia region. This article describes Russia's effort to improve its image towards the public of Indonesia through public diplomacy by using Russia Beyond (RBTH Indonesia) as a media. The authors apply Leonard, Stead, dan Smewing's (2002) three dimensions of public diplomacy as the tool of analysis, namely news management, strategic communications, and relationship building. The data was obtained from website and social media of Russia Beyond Indonesia, interviews with two related sources, and literature studies. The author concludes that public diplomacy carried out by Russia has used three dimensions of public diplomacy quite well, but further research needs to be done on the impact of these efforts in the improvement of Russia images in Indonesia.

Keywords: Indonesia, public diplomacy of Russia, Russia, Russia Beyond Indonesia 
Pada 21 Desember 2016, ratusan orang berdemonstrasi di depan kompleks Kedutaan Besar Rusia di Jakarta. Mereka mengusung berbagai poster dengan tulisan "Putin Go to Hell", "Suriah Kuburan Bagi Rusia", "No Komunis", "Stop Killing Muslim" dan kecaman-kecaman lainnya. Pada Februari 2019, Presiden Joko Widodo mengkritik lawan politiknya, yang menurutnya telah menyebarkan berbagai kebohongan, dengan menggunakan istilah 'Propaganda Rusia'. Kedua kejadian itu dapat menjadi indikasi betapa citra Rusia di Indonesia masih negatif. Indikasi ini selaras dengan hasil survei yang dilakukan Pew Research Center kepada publik Indonesia mengenai pandangan mereka terhadap Rusia. Pertanyaan dari survei tersebut adalah, "Apakah Anda memiliki pandangan yang baik, agak baik, agak buruk, atau buruk terhadap Rusia?” Sejak tahun 2007 hingga tahun 2017, pandangan baik publik Indonesia terhadap Rusia tidak pernah mencapai angka 50\%. Pandangan buruk publik Indonesia terhadap Rusia sering kali mencapai angka 40\% (Pew Research Center 2017). Bahkan, Indonesia menjadi negara dengan persepsi negatif tertinggi terhadap Rusia di kawasan Asia Tenggara.

Di tingkat global, citra Rusia di mata masyarakat dunia juga mengarah ke persepsi negatif. Masih dari Pew Research Center, ditemukan data bahwa 19 negara dari 37 negara yang disurvei memiliki pandangan negatif terhadap Rusia. Sebesar 40\% responden melihat Rusia secara negatif dan 34 \% di antaranya memandang Rusia dengan positif (Vice 2017). Pemerintah Rusia pada tahun 2003 juga melakukan survei terhadap publik Amerika Serikat (AS) yang menanyakan sepuluh hal teratas yang terkait dengan Rusia. Hasilnya, empat hal yang paling banyak dipikirkan oleh publik AS adalah komunisme, agen intelijen Uni Soviet (Komitet Gosudarstvennoy Bezopasnosti - KGB), salju, dan mafia. Seni dan budaya Rusia menempati posisi terakhir (Evans 2005). Presiden Vladimir Putin dalam salah satu pidatonya pun berkomentar bahwa citra Rusia di luar negeri tidak dibentuk oleh Rusia sendiri, melainkan hasil distorsi yang tidak mencerminkan situasi nyata maupun kontribusi Rusia terhadap peradaban global, sains, serta budaya (Putin 2012).

Sejak awal tahun 2000-an pemerintah Rusia telah menyadari pentingnya menumbuhkan citra positif di tengah publik dunia. Hal ini terungkap dalam beberapa dokumen resmi yang dikeluarkan oleh pemerintah Rusia (Feklyunina, 2008). Sejumlah penelitian terdahulu telah membahas bagaimana Rusia memanfaatkan media massa untuk memperbaiki image atau citranya di tengah publik dunia, sekaligus melawan narasi pemberitaan media Barat (Evans 2015; Sidorenko 2016).

Artikel ini membahas upaya perbaikan citra tersebut di tengah publik Indonesia melalui perspektif Diplomasi Publik. Foreign Policy Concept of Russian Federation merupakan sebuah dokumen yang berisi pemahaman Rusia tentang diplomasi publik, diadopsi pada tahun 2000 dan mengalami beberapa kali proses revisi. Dokumen yang digunakan di sini merupakan dokumen yang ditandatangani oleh Presiden Vladimir Putin pada tahun 2016. Dalam dokumen tersebut, dipaparkan beberapa fokus kebijakan luar negeri Rusia, terutama mengenai hubungan Rusia dengan negaranegara lain, antara lain bagaimana bentuk kerja sama yang diinginkan, promosi kebudayaan Rusia kepada pihak asing, serta terlibatnya Rusia di dalam organisasiorganisasi internasional. Ada satu poin di dalam dokumen tersebut yang menyebutkan bahwa meningkatnya posisi media massa Rusia serta penyampaian informasi kepada publik internasional yang menggunakan perspektif Rusia merupakan salah satu tujuan kebijakan luar negeri Rusia (The Ministry of Foreign Affairs of the Russian Federation 2016). Pemerintah Rusia memandang penting diplomasi publik dan hal ini dapat dilihat dari dapat dilihat dari investasi jutaan Dollar AS yang dilakukan Rusia dmelakukan aktivitas diplomasi publik (Avgerinos 2009).

Pendirian lembaga penyiaran internasional, Russia Today, pada tahun 2005 (sejak 2009 berubah nama menjadi RT) merupakan salah satu inisiatif diplomasi publik 
yang dilakukan oleh pemerintah Rusia. RT merupakan kanal berita 24 jam yang disiarkan ke seluruh dunia dari kantor pusatnya di Washington DC, menjangkau lebih dari 100 negara. RT awalnya berbahasa Rusia dan Inggris, namun kini juga menyiarkan tayangan berbahasa Spanyol dan Arab. RT berupaya mengklarifikasi kritik atau pemberitaan negatif dari Barat yang sering dimunculkan oleh media global yang menurut publik dan pemerintah Rusia 'unrelenting and unfair' (Finn 2008).

Pada 2007, pemerintah Rusia menerbitkan suplemen cetak bernama Russia Beyond The Headlines (RBTH) yang disisipkan pada dua koran terkemuka AS, The Washington Post dan The Daily Telegraph. Selanjutnya, suplemen RBTH juga diselipkan di 26 koran di 23 negara dalam 16 bahasa (Evans 2015). RBTH memiliki empat belas situs yang beroperasi dalam empat belas bahasa, yaitu Inggris, Jerman, Spanyol, Perancis, Kroasia, Italia, Portugis, Slovenia, Mandarin, Bulgaria, Makedonia, Serbia, Rusia, dan Bahasa Indonesia. RBTH juga aktif menggunakan media sosial seperti Twitter, Facebook, dan Instagram untuk menyebarkan informasi mengenai Rusia (Simonyan 2018).

Russia Beyond Indonesia atau sering disingkat 'RBTH Indonesia' pertama kali ditayangkan pada November 2013 dan menargetkan individu maupun kelompok yang aktif secara sosial, yang ingin menambah wawasan mengenai Rusia, baik untuk berwisata, bisnis, pendidikan, urusan profesional maupun untuk bersenang-senang (Simonyan 2018). Artikel ini akan menganalisis diplomasi yang dilakukan Rusia terhadap publik Indonesia melalui 'RBTH Indonesia' dengan menggunakan teori tiga dimensi diplomasi publik yang dikemukakan Leonard, Stead, dan Smewing (2002), yaitu news management, strategic communications, dan relationship building. Selanjutnya pembahasan akan dituliskan dalam beberapa bagian, yaitu konsep dan teori mengenai diplomasi publik, kebijakan Rusia terkait diplomasi publik, analisis terhadap diplomasi publik yang dilakukan Rusia melalui RBTH Indonesia, dan terakhir, kesimpulan.

\section{Diplomasi Publik}

Di dalam hubungan internasional, diplomasi merupakan salah satu aspek penting bagi aktor-aktor hubungan internasional, baik aktor negara maupun nonnegara dalam mencapai kepentingannya. Bertaut dengan pencapaian kepentingan ini, diplomasi publik dapat dipandang sebagai cara persuasif yang yang lebih efektif untuk mencapai tujuan tertentu di banding diplomasi yang menggunakan cara-cara paksaan-militer. Urgensi pentingnya diplomasi seperti ini, terutama mengemuka di dalam era perang dingin yang ketat, dengan sasaran untuk menghindarkan perang. Diplomasi publik bukannya ditujukan kepada negara, melainkan pihak non-negara, khususnya warga asing. Sharp (2009) mendefinisikan diplomasi publik sebagai proses diplomasi yang dilakukan oleh pemerintah terhadap masyarakat, baik masyarakat di negaranya maupun negara lain untuk meningkatkan kepentingan dan memperluas penyebaran nilai-nilainya. Sementara itu Tuch (1990) memahami diplomasi publik sebagai suatu usaha dari pemerintah untuk membentuk kondisi komunikasi di luar negeri dalam upaya untuk mengatasi adanya mispersepsi dan kesalahpahaman yang mempersulit hubungan antar negara (Tuch 1990). Alan K. Henrikson mendefinisikan diplomasi publik sebagai aktivitas yang dilakukan oleh pemerintah melalui media komunikasi publik dan melalui transaksi dengan berbagai entitas non-pemerintah (partai politik, perusahaan, asosiasi perdagangan, serikat pekerja, lembaga pendidikan, organisasi keagamaan, kelompok etnis, dan individu) dengan tujuan memengaruhi publik yang dapat berakhir dengan perubahan politik serta tindakan pemerintah negara tersebut kepada pelaku diplomasi publik (The Edward R. Murrow Center of Public Diplomacy). 
Diplomasi publik menenekankan pentingnya perkara komunikasi seperti yang terungkap di dalam pemahaman Edmund Gullion yang dikenal sebagai seorang praktisi diplomasi publik, yang menjabat Duta Besar Amerika Serikat di Kongo pada masa J. F. Kennedy. Pada tahun 1960-an, Edmund Gullion mengungkapkan pemahamannya bahwa diplomasi publik diarahkan kepada upaya memengaruhi publik asing (The Edward R. Murrow Center of Public Diplomacy). Di dalam konteks komunikasi, diplomasi publik itu meliputi pemanfaatan opini publik, pelaporan tentang ihwal luar negara, komunikasi antara diplomat dan wakil-wakil di luar negerinya serta proses komunikasi antarbudaya dlsb. Pentingnya memberi perhatian kepada aspek komunikasi di dalam diplomasi publik juga tampak berlaku pada berbagai sarjana/ pakar mengenai diplomasi jenis ini (Tuch 1990, Nye 2004, Wang 2006, Mellisen 2006, Cull 2008)

Leonard, Stead, dan Smewing (2002) memaparkan bahwa diplomasi publik berfokus pada pembangunan hubungan, yaitu memahami kebutuhan negara lain, budaya, serta masyarakatnya; berkomunikasi dari sisi pelaku; membenarkan persepsi; mencari hal atau aspek yang sama antara pelaku diplomasi publik dan target yang dimaksud. Leonard, Stead, dan Smewing lebih jauh menjelaskan adanya 4 tahap hierarki atas dampak yang dapat dicapai dari pelaksanaan diplomasi publik yaitu, (1) meningkatkan rasa keakraban masyarakat terhadap negara pelaku diplomasi publik dengan cara memperbarui citra negara dan memperbaiki persepsi atau opini yang tidak menguntungkan, (2) meningkatkan apresiasi masyarakat terhadap suatu negara dengan cara menciptakan persepsi positif, membuat masyarakat melihat masalah global dari perspektif yang sama, (3) memperkuat hubungan antara masyarakat suatu negara dengan negara pelaku diplomasi publik dalam berbagai bidang, mulai dari turisme, studi, ekonomi, hingga pemahaman nilai yang dianut negara pelaku diplomasi, dan (4) memengaruhi masyarakat agar mau melakukan investasi atau memberikan dukungan secara politik terhadap negara pelaku diplomasi publik (Leonard, Stead, dan Smewing 2002, 9-10).

Untuk mencapai tujuan-tujuan tersebut, Leonard, Stead, dan Smewing menyarankan agar pemerintah menjalankan diplomasi publikyang multidimensi. Ia mengembangkan konsep tiga dimensi diplomasi publik dari Joseph S. Nye dan memaparkan adanya tiga dimensi dalam aktivitas diplomasi publik, yaitu news management, strategic communications, dan relationship building.

Dimensi pertama, yaitu news management, membahas mengenai manajemen komunikasi dalam isu sehari-hari. Leonard, Stead, dan Smewing menggambarkan dimensi pertama sebagai dimensi yang mencerminkan kebutuhan yang semakin meningkat untuk menyelaraskan komunikasi dengan diplomasi tradisional. News management bertindak dalam menanggapi atau memberikan reaksi terhadap berita maupun acara, dengan memperhitungkan tujuan strategis pelaku diplomasi publik. News management harus bersifat fleksibel, reaktif, dan terhubung ke pemerintah. Pemberitaan reaktif yang disajikan akan melibatkan departemen dalam negeri dari pihak yang terkait dengan masalah atau isu yang dibicarakan. Pemberitaan ini sendiri diselenggarakan dalam hitungan jam maupun hari (Leonard, Stead, dan Smewing 2002, 12-13).

Dimensi kedua, yaitu strategic communications, merupakan kumpulan dari aktivitas yang menyerupai kampanye politik, yaitu menetapkan sejumlah pesan strategis serta merencanakan beberapa rangkaian kegiatan selama satu tahun atau lebih untuk memperkuatnya. Untuk melakukan hal ini, para pelaku diplomasi publik harus memiliki totalitas dalam pesan yang ingin disampaikan oleh negaranya dan dapat bekerja sama untuk mempromosikan pesan-pesan yang ingin disampaikan (Leonard, Stead, dan Smewing 2002, 15). 
Pada dasarnya, strategi komunikasi membutuhkan kemampun komunikasi yang proaktif, yang mengarah kepada perubahan persepsi. Komunikasi proaktif membutuhkan adanya keterampilan komunikasi yang sangat maju, perencanaan strategis serta anggaran, sumber daya, dan kemampuan untuk mengorganisasi acara yang dapat ditangkap oleh imajinasi (Leonard, Stead, dan Smewing 2002, 11). Umumnya pemerintah suatu negara telah memiliki kemampuan berkomunikasi yang baik berkenaan dengan pendirian mereka terhadap isu tertentu. Namun, kemampuan komunikasi ini menjadi kurang efektif dalam mengelola persepsi negara secara keseluruhan. Salah satu alasannya adalah adanya berbagai institusi yang bertanggung jawab untuk berurusan dengan politik, perdagangan, turisme, investasi, serta hubungan budaya. Untuk itu, perlu ada strategi komunikasi untuk memilah komunikan serta sasaran agar pesan tersampaikan dengan baik (Leonard, Stead, dan Smewing 2002, 14).

Terakhir, dimensi ketiga, relationship building, upaya pembangunan hubungan jangka panjang yang dapat dilakukan melalui pemberian beasiswa, pertukaran pelajar, pelatihan, seminar, konferensi, pembangunan jaringan nyata dan virtual, serta memberikan akses kepada media. Leonard, Stead, dan Smewing menekankan bahwa negara pelaku diplomasi publik harus memastikan agar individu atau publik memiliki pengalaman positif serta ada tindak lanjut dari berbagai aktivitas relationship building yang telah dilakukan. Munculnya pengakuan terhadap nilai-nilai positif pelaku diplomasi publik dari masyarakat luar negeri dianggap sebagai tujuan penting dari dimensi ketiga ini (Leonard, Stead, dan Smewing 2002, 18-20).

\section{Rusia dan Diplomasi Publik}

Diplomasi publik dalam bahasa Rusia diterjemahkan sebagai "общественная дипломатия" (obshchestvennaya diplomatiya). Terjemahan ini menimbulkan pemahaman diplomasi publik sebagai diplomasi dalam tingkatan organisasi publik. Hal ini menimbulkan kebingungan, di mana beberapa pakar pun yakin bahwa diplomasi publik tidak lebih dari dialog pada tingkatan organisasi nonpemerintah. Karenanya, terjemahan diplomasi publik kemudian diganti menjadi "публичная дипломтия" (publichnaya diplomtiya) yang memiliki pemahaman yang sama dengan public diplomacy (Dolinskiy 2012). Menurut pemerintah Rusia, tujuan utama diplomasi publik adalah untuk memengaruhi opini publik yang didasari oleh kebijakan-kebijakan luar negeri yang telah dikeluarkan oleh pemerintah. Bagi Rusia, diplomasi publik juga harus mematuhi kerangka hukum dan politik yang telah ditetapkan oleh pemerintah. Maka dari itu, segala bentuk diplomasi publik yang dilakukan, meskipun pemerintah tidak diberikan peran utama, tetap dilihat sebagai proses perpanjangan tangan dari pemerintah Rusia. Hal itu dikarenakan, setiap diplomasi publik yang dilakukan pasti harus merujuk kepada kerangka hukum dan politik yang berlaku yang dikeluarkan oleh pemerintah (Osipova 2012).

Kebijakan luar negeri Rusia yang mulai berfokus pada Asia merupakan salah satu bentuk seruan Neo-Eurasianisme yang diaplikasikan ke dalam kebijakan luar negeri Rusia. Selama ini, Putin juga disebut-sebut mulai mengaplikasikan Neo-Eurasianisme dalam dokumen Foreign Policy Concept of Russian Federation sejak tahun 2000 (Nugraha 2015). Selama pemerintahannya, dokumen tersebut mengalami beberapa kali perubahan, namun tidak semata-mata lepas dari Neo-Eurasianisme.

Dalam dokumen Foreign Policy Concept of Russian Federation terdapat beberapa topik yang difokuskan dalam pelaksanaan diplomasi publik Rusia. Pertama, pentingnya untuk menjelaskan atau memberikan gambaran tentang Rusia. Persepsi negatif dari 
publik luar negeri berasal dari kurangnya pemahaman tentang Rusia. Informasi yang tersebar di media-media Barat pun cenderung memberikan kesan negatif terhadap Rusia. Melawan citra negatif Rusia ini merupakan prioritas utama dari diplomasi publik yang dilakukan oleh pemerintah Rusia. Pemerintah Rusia menyadari bahwa terlalu banyak kesalahpahaman tentang citra dan identitas negara mereka yang disebarluaskan oleh jaringan media global. Maka dari itu, dengan memberikan informasi lebih banyak tentang Rusia, diharapkan kesalahpahaman terhadap Rusia dapat diminimalisasi (Feklyunina 2008).

Hal lainnya yang menjadi prioritas diplomasi publik Rusia adalah pembuatan programprogram budaya dan pendidikan. Bersamaan dengan diseminasi informasi yang benar mengenai Rusia, inisiatif di bidang budaya dan pendidikan dianggap sebagai suatu hal yang penting. Seperti yang tercantum di dalam Foreign Policy Concept of Russian Federation, Rusia memiliki tujuan untuk mempromosikan bahasa dan budaya Rusia. Hal itu kemudian dilaksanakan melalui pembentukan Rossotrudnichestvo, suatu organisasi yang bergerak dalam bidang pendidikan dan budaya (Filimonov 2010).

Salah satu contoh diplomasi budaya dan pendidikan yang dilakukan Rusia di Indonesia adalah dengan adanya Pusat Kebudayaan dan Ilmu Pengetahuan Rusia (PKR) di Jakarta. Aktivitas yang ada di PKR sendiri meliputi kuliah umum, kursus Bahasa Rusia, menonton film, menari tarian Rusia, serta pameran foto dan seni lukis. Selain itu, pemberian beasiswa dari Pemerintah Rusia juga selalu meningkat setiap tahunnya. Sebelumnya, Pemerintah Rusia hanya memberikan kuota sebanyak 50 penerima beasiswa dari Indonesia. Namun, pada tahun 2014 pemerintah Rusia meningkatkan kuota penerima beasiswa sebesar dua kali lipat apabila dibandingkan dengan tahuntahun sebelumnya. Pada tahun akademik 2014/2015, pemerintah Rusia menerima sebanyak 125 pelajar Indonesia untuk dapat melanjutkan studi di universitasuniversitas Rusia. Pada tahun 2018 sendiri, sudah ada 555 warga Indonesia yang mendaftarkan diri untuk beasiswa Pemerintah Rusia. Namun, kuota beasiswa sendiri hanya tersedia 161 orang, yang mencakup jenjang S-1 hingga S-3 (Al-Rasyid 2018).

Pesan penting yang ingin disampaikan Rusia melalui diplomasi publiknya adalah bahwa Rusia bukanlah negara yang agresif sebagaimana yang sering dipotret oleh media Barat, bahwa Rusia ingin bekerja sama yang saling menguntungkan dengan semua negara, dan bahwa Rusia mencita-citakan tatanan dunia yang lebih adil (Simons 2019).

\section{Russia Beyond dan Diplomasi Publik Rusia di Indonesia}

Hubungan antara Rusia dan Indonesia memiliki sejarah yang panjang. Pada tahun 1922-1991, Rusia adalah bagian dari Uni Soviet, sebuah negara terbesar dunia yang terdiri dari berbagai etnis, antara lain Rusia, Uzbek, Armenia, dan Ukraina. Pada 1991, Uni Soviet bubar setelah berbagai etnis itu, termasuk Rusia, memisahkan diri dan membentuk negara-negara independen. Pada tahun 1948, Uni Soviet mengakui kemerdekaan Indonesia secara de-facto. Kemudian, pada 3 Februari 1950 diberikan pengakuan secara de-jure yang menandakan terjalinnya hubungan diplomatik antara kedua negara. Hubungan Indonesia-Uni Soviet kian erat sejak Soviet mencalonkan Indonesia sebagai negara anggota Perserikatan Bangsa-Bangsa (PBB). Soviet juga banyak memberikan bantuan kepada Indonesia, terutama dalam bidang politik dan militer. Pada tahun 1962, Uni Soviet memberikan beasiswa kepada 700 mahasiswa Indonesia. Selain itu, berbagai kerja sama pembangunan pabrik, rumah sakit, Gelora Bung Karno, dan Patung Tani merupakan bukti eratnya hubungan antara kedua negara saat itu (Sriyono 2010). 
Titik balik hubungan antara Indonesia dan Uni Soviet terjadi ketika adanya peristiwa G3oS/PKI. Saat itu, PKI (Partai Komunis Indonesia) dituduh sebagai pelaku kudeta terhadap Presiden Sukarno. Menyusul peristiwa itu, terjadi pembantaian besarbesaran terhadap orang-orang yang dituduh berpaham komunis. Selanjutnya, ketika pemerintahan baru dibentuk, dipimpin oleh Presiden Suharto, paham komunis ditetapkan sebagai paham terlarang. Orang-orang yang dicurigai sebagai anggota PKI atau berpaham komunis dipenjarakan, anak-anak mereka juga diberi stigma buruk sehingga sulit berinteraksi di tengah masyarakat. Muncullah ketakutan massal terhadap komunisme. Dari kalangan relijius juga disebarkan narasi bahwa komunis adalah paham yang anti agama dan anti Tuhan. Karena Uni Soviet adalah negara yang berhaluan komunis, maka di tengah opini publik Indonesia, Rusia yang pernah menjadi bagian dari Soviet pun diidentikkan dengan komunis (Lebang 2010; Matanasi 2016).

Walaupun ada ketegangan hubungan antara kedua negara, kerja sama ekonomi tetap dilakukan. Antara lain, pada tahun 1974 kedua negara sepakat untuk memperbaharui Persetujuan Perdagangan dan Persetujuan Ekonomi dan Teknik. Tiga hari setelah bubarnya Uni Soviet pada 25 Desember 1991 Indonesia mengakui bahwa legal successor dari Uni Soviet adalah Federasi Rusia. Selanjutnya, hubungan politik antara kedua negara, Indonesia dan Rusia pun berjalan dengan sangat baik. Kerja sama di berbagai bidang, forum, serta peningkatan pemberian beasiswa Rusia kepada mahasiswa Indonesia terus meningkat (Sriyono 2010).

Namun demikian, persepsi negatif masyarakat Indonesia terhadap Rusia masih tinggi, seperti terungkap dalam survei yang telah dikutip sebelumnya. Oleh karena itulah Rusia memandang penting diplomasi publik terhadap masyarakat Indonesia dan pembuatan situs Rusia Beyond berbahasa Indonesia merupakan salah satu upaya dalam hal ini (Al Rasyid 2019, Simons 2019). Russia Beyond awalnya berada di bawah Rossiyskaya Gazeta, koran yang diterbitkan pemerintah Rusia. Sejak tahun 2017, Russia Beyond dikelola oleh RT, yang juga media pemerintah, tetapi sebagian sahamnya juga dimiliki swasta. Sejak berada di bawah RT, Russia Beyond tidak lagi memberitakan beritaberita yang sifatnya politik atau ekonomi. Sekarang misi dari Russia Beyond adalah untuk menjadi gerbang untuk segala hal yang berhubungan dengan Rusia, baik budaya, sejarah, masyarakat, pendidikan, maupun ilmu pengetahuan (Al Rasyid 2019).

Russia Beyond Indonesia (RBTH Indonesia) mulai beroperasi sejak 2013 langsung dalam format daring. Dalam situs RBTH Indonesia terdapat tujuh rubrik, yaitu teknologi dan sains, kuliner, ekonomi, discover Russia, sejarah, wisata, serta kuliah di Rusia. Rubrik 'Kuliah di Rusia' merupakan rubrik yang hanya ada di RBTH Indonesia yang memberikan informasi tentang para pelajar Indonesia yang melanjutkan studinya di perguruan tinggi di Rusia, informasi mengenai perguruan tinggi yang ada di Rusia, dan informasi mengenai beasiswa dari pemerintah Rusia untuk pelajar Indonesia.

\section{News Management dalam Pemberitaan RBTH Indonesia}

News management merupakan tindakan di mana pelaku diplomasi publik melakukan pemberitaan atau memberikan respons terhadap suatu berita atau isu atau acara (Leonard, Stead, dan Smewing 2002, 12). Pemberian respon ini dilakukan dengan secara aktif oleh RBTH Indonesia terutama karena banyaknya tersebar berita hoaks di media sosial Al-Rasyid (2019). Di antara hoaks yang sangat masif tersebar pada akhir tahun 2016 adalah bahwa Rusia membantu pemerintahan Bashar Assad di Suriah untuk 'membantai kaum Muslim di Aleppo'. Inilah yang memicu aksi-aksi demo yang penuh kecaman dan bahkan hinaan terhadap pemerintah Rusia, sebagaimana 
diceritakan di awal tulisan ini. Menurut Sulaeman (2017), pada Desember 2016, tentara Suriah dengan dibantu Rusia membombardir Aleppo Timur yang telah empat tahun dikuasai oleh milisi-milisi jihad yang berafiliasi dengan Al Qaida. Serangan dilakukan untuk menundukkan milisi-milisi jihad itu dan diawali dengan pemberian kesempatan untuk menyerah dan membuka jalur evakuasi kepada warga sipil.

Al-Rasyid (2019) menuturkan bahwa pada masa itu, RBTH Indonesia melalui media sosial dan artikel di laman web berupaya menjelaskan bahwa apa yang diberitakan oleh media Barat itu salah. Melalui jurnalis yang ada di Aleppo Timur, dikonfirmasi bahwa media Barat melebih-lebihkan apa yang terjadi dan menyudutkan Rusia. Namun setelah RBTH Indonesia berada di bawah manajemen RT, media ini tidak lagi memberitakan hal-hal yang berhubungan dengan politik dan karena itulah pemberitaan mengenai Suriah tidak lagi diangkat. RBTH Indonesia lalu berfokus pada pemberitaan tentang teknologi, budaya, wisata, pendidikan, serta sejarah Rusia.

Kasus lainnya adalah pernyataan seorang politisi muda bernama Tsamara Amani pada 5 April 2018. Pernyataan Amani direkam dalam video yang diunggah ke Twitter, berisi kritikan kepada Presiden Vladimir Putin dan tuduhan bahwa tindakan korupsi di Rusia dibiarkan begitu saja. Sekitar lima jam kemudian RBTH Indonesia melalui akun Twitter-nya merespon video tersebut, yang berisi sebagai berikut.

"Selamat malam@TsamaraDKI. Kami Russia Beyond, media Rusia yang (salah satunya) dalam bahasa Indonesia. Kami pikir di sini ada kesalahpahaman soal pengetahuan Anda tentang politik dan bahkan sistem pers di Rusia. Ini sangat disayangkan sekali. Kami tidak membela siapa pun, termasuk @fadlizon atau bahkan Presiden Putin. Namun, pernyataan Anda tentang negara kami, bahwa di Rusia tidak ada kebebasan beraspirasi seperti di Indonesia, ini menunjukkan kedangkalan wawasan. Pernyataan Anda juga sangat disayangkan karena hubungan antara kedua negara kita sangat baik. Anda mungkin bisa tidak sepakat dengan @fadlizon, tapi pernyataan Anda sebagai seorang politikus muda menunjukkan ketidakdewasaan. Kami pikir, Anda perlu lebih banyak riset soal negara kami. Kami tidak ikut campur dengan politik Indonesia. Kalau ada politikus Indonesia yang mengidolakan pemimpin kami, kami bisa apa? Anda bisa juga berdiskusi dengan@RusEmbJakarta untuk tahu lebih banyak tentang negara kami. Di Rusia memang ada korupsi, dan ya, besar. Itu betul. Peringkat kami di bawah Indonesia, itu juga betul. Namun, bukan berarti kami tidak melawan korupsi dan membiarkannya begitu saja seperti yang Anda katakan. Ini bukan pernyataan yang main-main. Tahukah Anda bahwa di Rusia pernah terjadi penangkapan pejabat secara massal sepanjang sejarah pasca-Soviet. Rusia pernah menghukum 8.800 pegawai negeri Rusia karena kasus korupsi (dalam tempo satu tahun). Banyak? Ya, tentu. Tapi bukan berarti kami MEMBIARKAN sama sekali. Kami lihat, Anda punya karier yang sedang naik. Karena itu, kami harap Anda bisa lebih bijaksana ke depannya ketika mengomentari negara lain, apalagi jika pengetahuan Anda tentang negara itu sangat minim. Jika itu kebetulan tentang Rusia, silakan cari tahu banyak hal dari kami." 


\section{Gambar 1}

\section{Respon RBTH Indonesia terhadap Tsamara Amany}

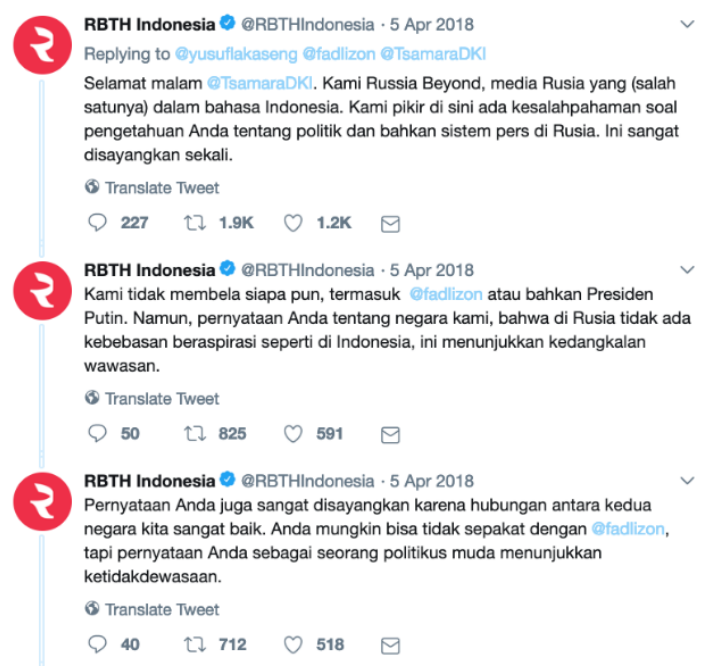

Respon ini segera menjadi sorotan. Beberapa media Indonesia menulis artikel mengenai polemik RBTH Indonesia versus Tsamara Amani. Publik Indonesia pun menaruh perhatian yang besar terhadap kelanjutan peristiwa tersebut. Satu hari kemudian, 6 April 2018, pada pukul 12:48, RBTH Indonesia menuliskan tweet yang menyatakan bahwa ketika video tersebut dirilis, pihaknya telah langsung menginformasikan kepada Kedutaan Besar Federasi Rusia untuk Republik Indonesia. Maka dari itu, Tsamara diundang untuk menghadiri press briefing yang rutin diadakan setiap bulannya di kediaman Duta Besar Federasi Rusia untuk Republik Indonesia, Lyudmila Vorobyeva. Namun, Tsamara tidak memenuhi undangan tersebut.

Contoh lainnya adalah pada 14 April 2018, terdapat berita yang tersebar luas di internet dari media Indonesia bahwa stasiun televisi Rusia memberikan himbauan untuk Perang Dunia III. RBTH Indonesia melihat berita tersebut dan memberikan respons melalui media sosialnya, Twitter dan Facebook. RBTH Indonesia melacak sumber berita tersebut dalam bahasa Rusia, lalu menjelaskan di mana letak kesalahan penerjemahan, dan menutup responnya dengan mengajak media Indonesia agar lebih berhati-hati, "Semoga media di Indonesia bisa lebih berhati-hati dalam membuat pemberitaan semacam ini, apalagi yang berpotensi menimbulkan kekhawatiran, seperti kemungkian perang dan sebagainya. Silahkan bertanya kepada kami untuk mengonfirmasi."

Hoaks lain yang tersebar adalah mengenai 'diwajibkannya poligami di Rusia'. Seperti biasa, klarifikasi RBTH diawali dengan menelusuri sumber awal berita dan memberitahukan bagaimana terjadinya disinformasi tersebut, lalu menjelaskan bahwa UU di Rusia tidak membolehkan poligami atau poliandri. RBTH Indonesia juga mengajak pembaca untuk bersikap logis dalam menerima berita dengan menulis, "kalau dikatakan: Rusia MEWAJIBKAN...," tentu ini tidak benar. Ini logika. Akal sehat."

Selanjutnya, pada November 2018 lalu, di media sosial tersebar video sekelompok orang yang mengibarkan bendera bertuliskan syahadat dengan keterangan video "kaum Muslim di Rusia melakukan protes atas pembakaran bendera HTI di Indonesia". RBTH dalam responsnya di Twitter menjelaskan bagaimana upaya mereka menelusuri sumber asli video sampai akhirnya ditemukan bahwa itu adalah video masyarakat negara bagian Dagestan yang memang mayoritas Muslim sehingga tidak aneh bila 
mereka mengibarkan bendera bertulisan syahadat. Namun, Hizbut Tahrir sudah dilarang di Rusia sejak 2003. Itu adalah video tahun 2013, sehingga sama sekali tidak ada kaitan dengan kasus pembakaran bendera HTI (atau sering disebut juga 'bendera tauhid') yang terjadi di tahun 2018.

RBTH menutup responsnya dengan cuitan bernada edukatif, "Zaman sekarang ini, informasi yang dikeluarkan oleh media yang kredibel pun belum tentu bisa kita telan mentah-mentah. Apalagi dari sumber-sumber tidak jelas. Apa, siapa, kapan, dimana, kenapa, dan bagaimana -inilah pertanyaan-pertanyaan yang harus kita jawab tiap kali menerima suatu informasi. Kita harus bersikap kritis!"

\section{Gambar 2}

\section{Respons RBTH Indonesia Perihal Aksi Muslim Rusia dan HTI}

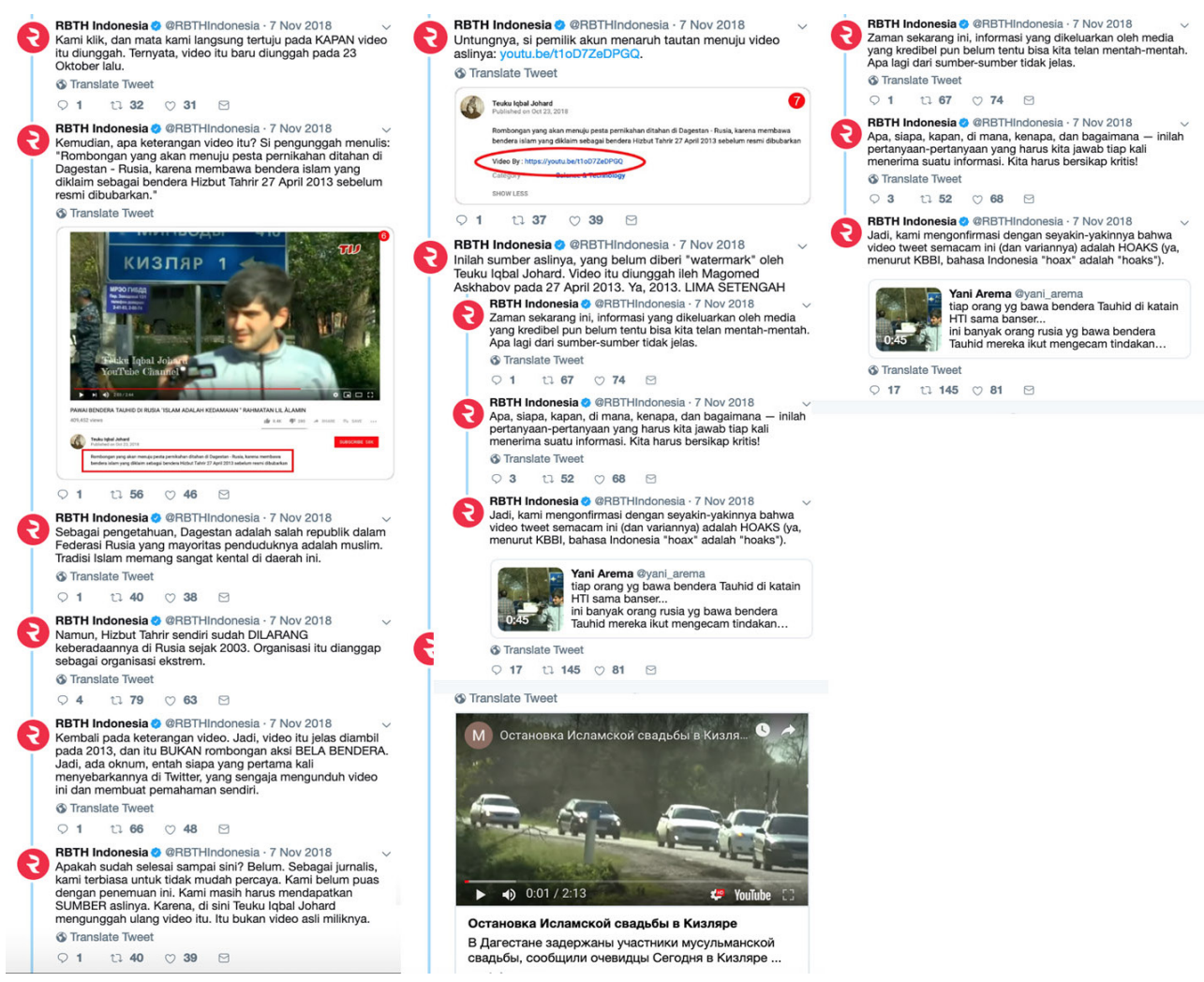

\section{Strategic Communications RBTH Indonesia}

Strategic communications berfokus pada perubahan persepsi sehingga perlu dilakukan berbagai perencanaan, meliputi sasaran pemberitaan serta pesan-pesan yang ingin disampaikan sangat dibutuhkan untuk mendapatkan hasil yang sesuai (Leonard, Stead, dan Smewing 2002, 14)

Pada tahun 2014, RBTH Indonesia mengadakan voting di laman webnya untuk mengetahui artikel apa yang paling disukai pembaca. Di antara artikel paling favorit berjudul 'Muslim di Rusia, Memang Ada?', 'Keragaman Kuliner Tatar, Makanan Halal Favorit di Rusia', dan 'Suka-Duka Berpuasa di Moskow'. Hal tersebut menunjukkan adanya ketertarikan yang cukup tinggi dari para pembaca Indonesia terhadap artikelartikel terkait Muslim di Rusia. Selain itu, pembaca-pembaca RBTH yang umumnya 
kaum muda berusia 20-30 tahun juga menyukai berita mengenai teknologi, sejarah, serta militer. Penggunaan media dalam jaringan, aktif di media sosial seperti Facebook dan Twitter juga salah satu upaya untuk menjangkau para anak muda yang menjadi target sasaran pemberitaan media RBTH Indonesia (Al-Rasyid 2019).

Apabila membandingkan pesan strategis yang disajikan oleh RBTH Indonesia dengan Russia Beyond di Amerika Serikat, terdapat beberapa hal yang berbeda. Berita yang disajikan RBTH kepada publik Amerika Serikat sering menyajikan persamaan antara Rusia dengan Barat (Evans 2015). Sementara di Indonesia, RBTH menggunakan strategi mencari persamaan antara kedua negara, misalnya dengan menyajikan banyaknya wisata halal di Rusia, serta kehidupan Muslim di Rusia. Selain itu. RBTH Indonesia berusaha menjawab berbagai isu sensitif bagi publik Indonesia, terutama terkait komunisme.

Pada awal tahun 2014, RBTH Indonesia menerbitkan sebuah artikel yang berjudul ‘Tiga Persepsi Mengenai Orang Rusia yang Salah' yang salah satunya memaparkan bagaimana persepsi yang salah itu adalah orang Rusia adalah komunis. Artikel tersebut menjelaskan bahwa memang masih ada sebagian warga Rusia yang menganut paham komunisme, tetapi partai komunis kini sudah tidak memiliki pengaruh signifikan di Rusia. Artikel yang ditulis pada 7 Februari 2014 itu pun kembali dipublikasikan oleh RBTH Indonesia pada 6 Maret 2019 melalui media sosial Twitter. Artinya, dalam kurun waktu lima tahun, RBTH Indonesia masih merasa perlu untuk mengedukasi dan menyampaikan pesan mengenai persepsi-persepsi yang salah mengenai orang Rusia.

Pada tahun 2017 RBTH Indonesia memublikasikan sebuah artikel yang membahas mengenai bagaimana Rusia pernah menjadi negara komunis. Penjelasan yang ada di dalam artikel tersebut memberikan pemahaman sejarah yang mendalam. Artikel tersebut kemudian ditutup dengan penekanan bahwa setelah era Brezhnev pada tahun 1970-an, partai komunis menjadi partai yang semakin jauh dari rakyat. Penekanan ini bertujuan untuk memberikan informasi bahwa komunisme dan Rusia hanya bagian dari sejarah, saat ini komunisme di Rusia tidak memiliki pengaruh yang besar terutama di dalam pemerintahan Rusia.

Pada 16 April 2018, RBTH Indonesia menuliskan artikel yang berjudul 'Apakah Rusia Adalah Negara Komunis?’ Artikel tersebut membahas secara mendalam mengapa Rusia bukanlah negara komunis. Lagi-lagi, paham komunisme hanya dianggap sebagai suatu hal yang ada di masa lalu. Di Rusia sendiri, meskipun ada beberapa atribut-atribut yang menggambarkan mengenai komunisme, itu hanya sebagian kecil dari peninggalan sejarah, tidak memiliki arti yang mendalam.

Pada Juli 2018, RBTH Indonesia melakukan wawancara dengan beberapa pelajar dari Indonesia. Para pelajar Indonesia ini diberikan pertanyaan-pertanyaan mengenai stereotip Rusia dan apa yang berubah dari sebelum mereka pergi ke Rusia dan setelah tinggal di Rusia. Salah satu pelajar Indonesia menjawab stereotip mengenai Rusia yang masih sering dianggap sebagai negara komunis. Ia menyatakan bahwa apabila melihat realitas sekarang, sudah tidak relevan lagi bila Rusia masih dikaitkan sebagai negara komunis dan menyeramkan. Dengan mendapatkan pernyataan langsung dari warga Indonesia, informasi yang disampaikan melalui RBTH Indonesia pun dapat lebih dipercaya oleh para pembacanya.

Mengenai kehidupan kaum Muslim di Rusia juga sering ditulis oleh RBTH Indonesia. Hingga saat ini, terdapat 332 artikel yang ditulis terkait hal ini. Setiap tahunnya, RBTH Indonesia selalu menuliskan artikel bagaimana para Muslim di Rusia melaksanakan puasa di bulan Ramadan dan bagaimana mereka merayakan Idul Fitri dan Idul Adha. Pelaksanaan ibadah di Hari Raya, foto-foto bagaimana padatnya jamaah ketika 
melaksanakan sholat di Hari Raya sering ditampilkan dan mendapatkan banyak perhatian. Selain itu, ucapan dari Presiden Vladimir Putin mengenai perayaan Hari Raya Muslim pun selalu dirilis bersamaan dengan artikel mengenai kehidupan Muslim di Rusia yang sedang merayakan Hari Raya.

RBTH Indonesia juga memberikan penjelasan mengenai isu-isu sensitif, misalnya mengenai pelarangan jilbab. Dengan terbuka, RBTH menuliskan karena Rusia adalah negara ferderal atau gabungan dari beberapa negara bagian, tiap-tiap negara bagian memiliki aturan tersendiri. Penjelasan tentang hal ini ditulis dalam artikel 'Jilbab di Rusia: Diwajibkan dan Dilarang' (ditulis pada 4 November 2016) dan sebelumnya, selama tahun 2014 dan 2015 juga ada beberapa artikel yang menjelaskan pembatasan penggunaan jilbab di Rusia, terutama di lingkungan sekolah. Rusia merupakan negara yang mewajibkan sekaligus membatasi penggunaan jilbab. Kewajiban menggunakan jilbab ada di Republik Chechnya, menjadikan republik ini satu-satunya wilayah yang mewajibkan perempuan untuk menggunakan jilbab. Namun, di Republik Mordovia dan Stavropol Krai penggunaan jilbab dilarang di sekolah dan universitas. Republik Tatarstan justru menjadi wilayah yang membebaskan perempuan Muslim untuk menggunakan jilbab ataupun tidak. Sementara itu, Kremlin (pemerintah pusat) tidak mengemukakan pendapat terkait pro kontra yang ada di beberapa wilayah. Hal itu dilakukan karena Kremlin tidak ingin berpihak.

RBTH Indonesia juga secara terbuka menuliskan kesulitan mendapatkan tempat ibadah yang dihadapi oleh Muslim di Rusia. Meskipun banyak masjid peninggalan sejarah, jumlah masjid tersebut tidak sebanding dengan banyaknya Muslim di Rusia. Di Moskow sendiri, hanya terdapat empat masjid. Walaupun Masjid Agung Moskow adalah masjid terbesar di Eropa, tetap saja tidak bisa menampung seluruh Muslim Moskow yang ingin beribadah selama perayaan hari-hari besar Islam. Perayaan Hari Raya Idul Fitri dan Idul Adha di Moskow mengalami kesulitan karena sedikitnya masjid sehingga kaum Muslim terpaksa harus menunaikan sholat Eid di jalanan sekitar masjid.

Bagi pemerintah Rusia, besarnya jumlah Muslim di negara mereka (Islam adalah agama terbesar kedua di Rusia) justru memberikan peluang untuk meningkatkan hubungan baik dengan negara-negara Muslim. Rusia mengembangkan berbagai program yang dapat menarik turis Muslim, misalnya program Halal Friendly yang dirancang untuk menyediakan kebutuhan akomodasi, rencana perjalanan, serta makanan tradisional yang telah diadaptasi menurut standar halal kaum Muslim. Peluncuran program ini ditujukan untuk meningkatkan wisatawan dari negara-negara berpenduduk mayoritas Muslim. RBTH Indonesia juga banyak menulis artikel yang membahas Halal Friendly dan tempat-tempat wisata di Rusia.

Teknologi militer Rusia telah menjadi suatu hal yang menarik bagi para pembaca, terutama publik Indonesia. Seperti yang disampaikan oleh Fauzan Al-Rasyid, mayoritas pembaca RBTH Indonesia adalah kaum pria. Hal ini kemudian menjadikan rubrik teknologi dan sains sebagai rubrik favorit bagi pembaca pria. Sejak berdirinya RBTH Indonesia hingga April 2019, telah ada 2.693 artikel yang ditayangkan dalam rubrik teknologi dan sains. 283 artikel di antaranya merupakan artikel teknologi militer Rusia yang berkaitan dengan Indonesia, seperti ketertarikan Indonesia terhadap pesawat Rusia, maupun kerja sama yang dilakukan kedua negara dalam bidang teknologi militer. 


\section{Relationship Building dalam Pemberitaan RBTH Indonesia}

Relationship building merupakan upaya membangun hubungan jangka panjang yang bisa dilakukan melalu pemberian beasiswa, pertukaran pelajar, maupun pemberian akses ke saluran media ((Leonard, Stead, dan Smewing 2002, 18). Pemerintah Rusia selama ini telah banyak memberikan beasiswa pendidikan kepada pelajar Indonesia yang ingin melanjutkan studi ke Rusia. Beasiswa yang diberikan oleh pemerintah Rusia sendiri terus meningkat yang diikuti dengan meningkatnya minat dari para pelajar Indonesia untuk melakukan studi di Rusia. RBTH Indonesia dalam hal ini menjalankan peran sebagai pemberi informasi mengenai beasiswa pemerintah Rusia, melalui program khusus bernama 'Kuliah di Rusia'. Di antara informasi yang diberikan adalah kompetisi untuk studi di Rusia yang tidak ketat, pendidikan yang berkualitas, kondisi negara yang aman apabila dibandingkan dengan negara-negara di Eropa, seperti Perancis atau Jerman yang sebagian masyarakatnya masih bersikap antiimigran, info beasiswa, kehidupan sehari-hari sebagai pelajar di Rusia, serta stereotipstereotip yang ada mengenai Rusia. Berbagai kemudahan dalam proses aplikasi visa pelajar, cara belajar Bahasa Rusia, serta informasi dari Perkumpulan Pelajar Indonesia di Rusia pun dengan jelas tertulis di dalam rubrik 'Kuliah di Rusia'.

Peningkatan hubungan jangka panjang juga dapat dilakukan dengan pemberian akses ke saluran media. RBTH Indonesia sebagai media tidak hanya aktif dalam menuliskan artikel di laman webnya, namun juga aktif dalam berinteraksi dengan para pembacanya melalui media sosial yang dimilikinya. Twitter, Instagram, serta Facebook merupakan sosial media yang dimiliki oleh RBTH Indonesia. Berinteraksi dengan menggunakan Bahasa Indonesia dengan para pembacanya memberikan nilai tambah bagi RBTH Indonesia. Dari ketiga media sosial tersebut, Facebook masih menempati posisi pertama dalam hal interaksi antara pembaca, yaitu publik Indonesia, dengan media RBTH Indonesia. Upaya komunikasi yang intens dilakukan RBTH Indonesia dengan cara tidak menutup kolom komentar dan memberikan tanggapan atas pertanyaanpertanyaan yang muncul dari para pembaca. Hal ini merupakan upaya untuk berinteraksi secara langsung agar tercipta hubungan yang lebih dekat antara publik Indonesia dengan bangsa Rusia. Dengan memberikan akses kepada publik Indonesia untuk menggunakan saluran media Rusia, dalam hal ini RBTH Indonesia, pemerintah Rusia telah melakukan upaya pembangunan hubungan jangka panjang dengan publik Indonesia.

\section{Simpulan}

Persepsi publik Indonesia terhadap Rusia yang masih relatif negatif membuat pemerintah Rusia memberikan perhatian khusus dengan melakukan diplomasi publik terhadap publik Indonesia. Melalui analisis yang dilakukan, ditemukan bahwa pelaksanaan diplomasi publik Rusia melalui media Russia Beyond The Headlines Indonesia (RBTH Indonesia) berlangsung di dalam tiga dimensi diplomasi publik, news management, strategic communications, dan relationship building. RBTH secara konsisten melaksanakan ketiga dimensi tersebut, antara lain dengan mengatur rubrik-rubrik dan memublikasikan berita atau artikel yang memang dicari dan disukai publik Indonesia, secara aktif mengklarifikasi berbagai hoaks yang tersebar di publik Indonesia terkait Rusia, dan melakukan interaksi komunikasi yang hangat dan edukatif melalui media sosial. RBTH Indonesia juga mengikuti perkembangan zaman yaitu dengan mengoptimalkan media online, terutama media sosial, dalam penyebaran informasi mengenai Rusia. Penelitian lanjutan perlu dilakukan untuk mengetahui hasil dari upaya pemerintah Rusia, khususnya melalui Russia Beyond, dalam melakukan diplomasi publiknya di Indonesa. 


\section{Referensi}

\section{Buku}

Lebang, T, 2010. Sahabat Lama, Era Baru: 6o Tahun Pasang Surut Hubungan Indonesia-Rusia. Jakarta, Grasindo.

Leonard, M., Stead, C., and Smewing, C. 2002. Public Diplomacy. London, The Foreign Policy Centre.

Melissen, J., 2005. The New Public Diplomacy: Soft Power in International Relations. New York, Palgrave Macmillan.

Nye, J, 2004. Soft Power: The Means to Success in World Politics. New York: Public Affairs.

Sharp, P, 2009. Diplomatic Theory of international Relations. Cambridge, Cambridge University Press.

Sriyono, A. A, 2010. 6o Tahun RI-Rusia dalam Sahabat Lama, Era Baru: 6o Tahun Pasang Surut Hubungan Indonesia-Rusia. Jakarta, Grasindo.

Sulaeman, D. Y, 2013. Prahara Suriah. Jakarta, Pustaka IIMaN.

Tuch, H. N., 1990. Communicating With the World: US Public Diplomacy Overseas. London, Palgrave Macmillan.

\section{Jurnal dan Jurnal Daring}

Avgerinos, K. P., 2009. "Russia's Public Diplomacy Effort: What the Kremlin is Doing and Why it's Not Working", Journal of Public and International Affairs, 20: 115-131.

Cull, N.J., 2008. "Public Diplomacy: Taxonomies and Histories", The ANNALS of the American Academy of Political and Social Science, 616 (1): 31-54.

Feklyunina, V., 2008. "Projecting Russia in the West", Europe-Asia Studies, 6o, (4): 605-629.

Nugraha, A., 2015. "Neo-Eurasianism in Russian Foreign Policy: Echoes from the Past or Compromise with the Future?", Global Strategis, 9, (1): 95-110.

Wang, J., 2006. "Public Diplomacy and Global Business", The Journal of Business Strategy, 27, (3): 49-58.

\section{Artikel Daring}

Al-Rasyid, F, 2018. Tinggi Peminat, Pendaftaran Beasiswa Pemerintah Rusia Dibuka hingga Akhir Februari [online]. Dalam https://id.rbth.com/kuliah-di-rusia/79810pendaftaran-beasiswa-rusia-2018-wyx [diakses 14 November 2019].

Dolinskiy, A, 2013. How Moscow Understands Soft Power [online]. Dalam https:// russia-direct.org/analysis/how-moscow-understands-soft-power [diakses 26 Januari 2019]. 
Evans, J, 2005. Spinning Russia [online]. https://foreignpolicy.com/2005/12/01/ spinning-russia/ [diakses 11 Desember 2018].

Filimonov, G, 2010. Russia's Soft Power Potential [online]. Dalam https://eng. globalaffairs.ru/number/Russias-Soft-Power-Potential-15086 [diakses 21 Januari 2019].

Finn, P, 2008. Russia Spends Heavily to Buff Up its Image for Western Nations [online]. Dalam http://www.archive.boston.com/news/world/articles/2008/03/og/russia spends heavily to buff up its image for western nations/ [diakses 10 Oktober 2018].

Matanasi, P, 2016. Hantu Komunisme yang Masih Saja Ditakuti [online]. Dalam https://tirto.id/hantu-komunisme-yang-masih-saja-ditakuti-b4Td [diakses 19 Juli 2019].

Pew Research Center, 2017. Global Indicators Database: Opinion of Russia [online]. Dalam http://www.pewglobal.org/database/indicator/27/country/101/response/ Unfavorable/ [diakses 10 Oktober 2018].

Simonyan, M, nd. Tentang Kami [online]. Dalam https://id.rbth.com/about [diakses 10 Oktober 2018].

The Ministry of Foreign Affairs of the Russian Federation, 2016. Foreign Policy Concept of the Russian Federation [online]. Dalam http://www.mid.ru/en/ web/guest/foreign policy/official documents/-/asset publisher/CptICkB6BZ29/ content/id/2542248 [diakses 10 Juli 2019].

Vice, M, 2017. Publics Worldwide Unfavorable Toward Putin, Russia [online]. Dalam http://www.pewglobal.org/2017/08/16/publics-worldwide-unfavorable-towardputin-russia/ [diakses 10 Oktober 2018].

\section{Lain-Lain}

Al-Rasyid, F (jurnalis RBTH Indonesia). Wawancara 13 Februari 2019.

Evans, D., 2015. Russian Soft Power Cultivation in the United States of America: A Media Content Analysis of Russia Beyond the Headlines. University of Tartu.

Osipova, Y., 2012. New Russian Public Diplomacy: Conceptualization, Practice and Limitations. Presented at 2012 ISA Annual Convention, San Diego, California, United States of America. [online] http://files.isanet.org/ConferenceArchive/ d8f26c6d8298478ea6920dfafof3aed2.pdf [diakses 11 Desember 2018].

Sidorenko, A., 2016. Russia Today: An Alternative View on Soft Power. Simon Fraser University.

Simons, G., (Peneliti di Institute for Russian and Eurasian Studies, Uppsala University, Sweden). Wawancara via email 28 Januari 2019.

The Edward R. Murrow Center of Public Diplomacy (n.d.). Definitions of Public Diplomacy. 
Russia Beyond Indonesia: Image Transforming Effort Through Public Diplomacy 